\title{
The Impact of Airline Mergers on Quality: Why Do Different Mergers Have Such Different Effects?
}

Daniel Rijken ${ }^{1}$

Vincent (V.A.C.) van den Berg ${ }^{2}$ 
Tinbergen Institute is the graduate school and research institute in economics of Erasmus University Rotterdam, the University of Amsterdam and VU University Amsterdam.

Contact: discussionpapers@tinbergen.nl

More TI discussion papers can be downloaded at the Tinbergen Site

Tinbergen Institute has two locations:

Tinbergen Institute Amsterdam

Gustav Mahlerplein 117

1082 MS Amsterdam

The Netherlands

Tel.: +31(0)20 5984580

Tinbergen Institute Rotterdam

Burg. Oudlaan 50

3062 PA Rotterdam

The Netherlands

Tel.: +31(0)10408 8900 


\title{
The impact of airline mergers on quality: Why do different mergers have such different effects?
}

Version of 22 Augustus 2017

\author{
Daniel Rijken $^{\mathrm{a}}$ and Vincent A.C. van den Berg ${ }^{\mathrm{a},{ }^{*}, \#}$ \\ a: Department of Spatial Economics, VU University, De Boelelaan 1105, 1081HV Amsterdam, \\ The Netherlands \\ *: Corresponding author: email: v.a.c.vanden.berg@vu.nl, tel: +31 205986049 \\ \#: Affiliated to the Tinbergen Institute, Gustav Mahlerplein 117, 1082 MS Amsterdam
}

\begin{abstract}
We investigate the impacts of five airline mergers on one quality dimension, namely route frequency. We use monthly data on routes between the largest 64 US cities from 1999 to 2016. On average, the mergers decrease the frequency, but there are large differences between the five mergers. We hypothesize that these differences resulted from differences in the market and network structures. Our estimations indicate that, if a destination has more connecting flights of the merging airlines, the merger is less detrimental to the frequency, possibly because the merger removes serial marginalization in the quality and price setting. For the market structure effect, we use two distinct set-ups. In the first set-up, the effects of mergers depend on a lagged variable measuring the current market structure. On routes with stronger competition, mergers decrease the frequency more, possibly due to a larger effect on the market structure. When the merging airlines control all the flights, mergers have almost no impact on the frequency. The second set-up uses the market structure before the merger. When one of the merging partners controlled all the flights between two airports, the merger does not directly affect the market structure and seems to have little to no impact on the frequency. Surprisingly, if both partners were flying between two airports before the merger, this merger does not seem to be more harmful to the frequency than when only one partner was operating on the route.
\end{abstract}

Key words: Mergers, quality, airlines, schedule delay, frequency

JEL codes: D22, L13, L93, R40 


\section{Introduction}

The media, practitioners and travellers are increasingly concerned that mergers and acquisitions (henceforth mergers for brevity) decrease the quality offered by airlines. Scholars and regulators have extensively studied the effects of mergers on prices, but only a few papers have examined the effects on quality. Although mergers have a bad reputation for lowering the service quality, this is not necessarily the case. Rijken (2016) found that one European airline merger led to an increased frequency and thus a higher quality. Chen and Gayle (2013) found that the Delta/Northwest and Continental/United mergers raised the routing quality on routes on which the merging partners did not compete. It is important for airline managers and regulators to understand and predict correctly the effects of mergers on the quality of service and to determine why the effects may be different in different cases.

The literature has found that a merger may reduce prices as costs due to synergies or economies of scale, but mergers also change the market structure. If the merging airlines directly competed on a route, as they offered parallel services, then the merger probably increased their market power and thus their prices. Conversely, in the spirit of Economides and Salop (1992), if the airlines offered connecting serial flights, then users had to fly by two airlines with market power, and a merger would actually reduce the prices by eliminating the serial marginalization and the resulting double mark-ups. Accordingly, the empirical literature on the price effects of mergers has reached mixed conclusions. Borenstein (1990) studied two cases: Northwest's merger with Republic Airlines led to significantly higher prices in the year after the merger, while Trans World Airlines' purchase of Ozark did not exert a significant impact on prices and mostly seemed to decrease them. Morrison (1996) noted that the airlines and the market may need years to adjust to a merger, and he indeed found that the effects of the above two mergers were much smaller in the long run. Kim and Singal (1993) and Kwoka and Shumilkina (2010) found that their mergers increased prices, while Luo (2014) found that the Delta/Northwest merger had little effect on prices.

We study the effects of five mergers of US airlines on the schedule delay as measured by the flight frequency. The schedule delay is the difference between a consumer's preferred departure time and the actual departure time. It is difficult to measure directly, and therefore researchers often use the flight frequency as a proxy. Passengers value a flight schedule with more departure times, as this allows them to find a departure time that is closer to their preferred departure time (Richard, 2003). ${ }^{1}$ Morrison and Winston (1995) and Berry and Jia (2010) empirically found that the flight frequency strongly influences the choice of airline and thus is an important form of quality.

We find that on average our mergers significantly decrease the frequency. Moreover, the effect seems to be stronger in the long run than in the short run. This suggests that airlines and

\footnotetext{
${ }^{1}$ Frequency does not fully measure the schedule delay, but it seems to be a good proxy. A possible issue is that merged airlines may have had flights departing at times of the day that were close together before the merger (Bilotkach, 2007).
} 
markets also need time to adjust to mergers in their choice of quality. There are marked differences in the impacts of the five mergers. For instance, the merger between Continental and United led to a large and significant decrease in flight frequency, while the US Airways and America West merger led to smaller changes, which are insignificant in some specifications.

Consequently, we find that the effects of mergers on the frequency vary substantially over different mergers, just as was the case for prices. This raises the following question: why is this so? Building on Borenstein (1990), Chen and Gayle (2013) and Czerny et al. (2016), we hypothesize that it results from differences in the network and competition structure.

Although we find that mergers on average lower the quality, this is not necessarily always true. Mergers may lower costs, as for instance Gayle and Le (2013) found for two recent mergers. This would allow for lower prices and thus more passengers and higher frequencies. Mergers may also lower the marginal cost of supplying quality, and thus, all else being equal, result in a higher quality. A final reason why mergers may raise the frequency is by removing serial marginalization. Czerny et al. (2016) show that serial marginalization may occur not only in price setting but also in quality setting: each independent airline ignores that, if its sets a higher quality level, this raises the profit of the other airline. Hence, if two serial airlines merge, they will set a higher quality level for the same number of passengers and cost structure. Therefore, if merging airlines offer more connections at a destination, this may make the merger better for the frequency.

Still, mergers may also increase the market power, which could result in higher prices, fewer passengers and less need to invest in quality. This situation would lower the quality, and more so the more the merger affects the market structure between two airports. If one of the partners already had a monopoly, the merger will have little influence on the market structure and may thus have little impact on the frequency setting. If both merging airlines were flying between two airports, the merger should have the largest effect.

Our contribution is twofold. First, although our mergers have been analysed in other recent papers, we have more data: for more airports, for more airlines and for a longer time span. We use the T100 dataset from the US Department of Transportation, whereas other recent papers used other datasets from this department. Second, we aim to explain why the different mergers have had such different impacts on the frequency. Our estimations support the idea that the market and network structures alter the impact of mergers. Nevertheless, differences remain in the effects of the five mergers even after we control for all of these issues.

Borenstein (1990) investigated the effects of two mergers on the loadfactor and found that they on average led to higher loadfactors. On the one hand, a higher loadfactor indicates a more efficient operation as the planes are less empty; on the other hand, a higher loadfactor means more crowded planes, implying a lower quality. Chen and Gayle (2013) studied the effect of two different mergers on routing quality, which is the ratio of non-stop flight 
distance to a trip's actual distance that can be longer due to hubbing. The mergers increased the routing quality of the merging firms on routes on which they did not compete; on routes on which they did compete, the merger lowered their routing quality. Gil and Kim (2016) investigated the impacts of mergers on the frequency offered by other airlines. They concluded that, on routes on which both merging airlines were present, the merger increased the frequency of the other airlines, but the effect was insignificant in the long run.

Prince and Simon (2014) studied the influence of mergers on travel times, cancelations, frequency and customer complaints. They determined that, in the short run, mergers may have slightly increased the travel times of the merging airlines, but, in the long run, their travel times decreased. Regarding the frequency, they found that the merging airlines' frequencies decreased but not significantly. Conversely, we find a very significant result. This difference is probably because we have a longer time span and more routes; the econometric set-ups are almost the same (see section 3).

There are related fields for which our results may have implications: for example, mergers and the quality of banks (Focarelli and Panetta, 2003; Sapienza, 2002), the quality of health care (Ho and Hamilton, 2000; Mutter et al., 2011; Romano and Balan, 2011) or the quality of newspapers (Fan, 2013). Finally, there is an extensive literature on the effects of airline alliances on prices and quality. On a route with an alliance, the partners make agreements on the service characteristics, code sharing, frequency, departure times, and sometimes even fares and revenue sharing (Ito and Lee, 2007; Gayle, 2013; Bilotkach and Hüschelrath, 2015).

The remainder of this paper is structured as follows. Section 2 will discuss the data, the mergers and the econometric set-ups. Section 3 will analyse the base regressions, finding marked differences in the effects of the different mergers. Section 4 empirically finds that the network and market structures alter the impact of mergers on the frequency. Sections 3 and 4 also perform extensive sensitivity analyses. Section 5 concludes.

\section{Data, hypotheses and econometric set-up}

Our mergers are given in Table 1. The closing dates are when the operations of the two carriers were completely integrated. These dates will be used to make the distinction between the pre-merger and the post-merger phase in our analysis.

Table 1: List of analysed mergers

\begin{tabular}{lll}
\hline Merged entities & Closing date & Resulting entity \\
\hline Southwest Airlines (WN) - AirTran Airways (FL) & 28 December 2014 & Southwest Airlines \\
United Airlines (UA) - Continental Airlines (CO) & 1 October 2010 & United Airlines \\
Delta Airlines (DL) - Northwest (NW) & 31 December 2009 & Delta Airlines \\
US Airways (US) - America West Airlines (HP) & 27 September 2005 & US Airways \\
American Airlines (AA) - Trans World Airlines (TW) & 1 April 2001 & American Airlines \\
\hline
\end{tabular}


The data is from the United States Department of Transportation. The specific dataset that we use is the T-100 Domestic Segment (U.S. Carriers). ${ }^{2}$ It includes monthly data reported by US carriers on their domestic non-stop flights. Only flights between US airports are included. The data spans 19 years from January 1998 until January 2016.

Following Aguirregabiria and Ho (2012) and Chen and Gayle (2013) among others, we focus on air travel between the 64 largest US cities. Consequently, the dataset is limited to 63 airports. Following Pai (2010), we only include observations with more than 19 departures. This ensures that flights are indeed regularly scheduled. We focus on the passenger industry, and all cargo flights are thus deleted. Following Prince and Simon (2014), we combine airlines that merge at some point into one airline for the entire sample: accordingly, their observations between the same origin-destination pair in the same month are summed. This prevents the problem whereby sometimes a brand disappears (from a route) following a merger and especially after an acquisition. All this enables the analysis of the total effect of a merger on the route frequency of the two airlines combined. As Table 2 shows, the eventual dataset contains a massive 740659 monthly observations.

\section{Table 2: General information dataset}

\begin{tabular}{lc}
\hline Number of observations & 740659 \\
Number of carriers & 72 \\
Number of different O-D carrier combinations & 12508 \\
Number of time periods & 217 \\
\hline
\end{tabular}

Fig. 1 plots the combined mean frequencies of the merged carriers over time. The vertical dashed lines indicate the closing dates. Based on these plots, it is impossible to draw conclusions on the effect of mergers, as any possible effect is obscured by other changes and airline idiosyncratic effects. To draw conclusions, fixed-effect regressions are needed. The monthly frequency between two airports, as given by the performed departures, is the dependent variable. We will also present estimations with the log of the frequency as the dependent variable. Chen and Gayle (2013) also used flights between two airports as their unit of observation, but they used the on-time performance dataset. Prince and Simon (2014) looked at itineraries of passengers using the Origin and Destination Survey (DB1BMarket) dataset. Therefore, in their setting a passenger hubbing and thus using two flights would constitute one observation, while in our setting the two legs of this journey would be in separate observations. Table 3 gives the descriptive statistics of the important variables.

\footnotetext{
2 The data was downloaded for each year seperatly from https://www.transtats.bts.gov/DL_SelectFields.asp?Table_ID=311 in May 2016, see also the main data website https://www.transtats.bts.gov/DATAINDEX.ASP. Scripts for data set-up and analysis are avialable on request. The intial data calculation were performed in R studio 1.0.44 using R 3.3.3 and the estimations in STATA/se 14.1. In R the clustering of standard errors proved too time consuming, although the results are identical.
} 
Fig. 1. Average number of departures for the five merging partners combined

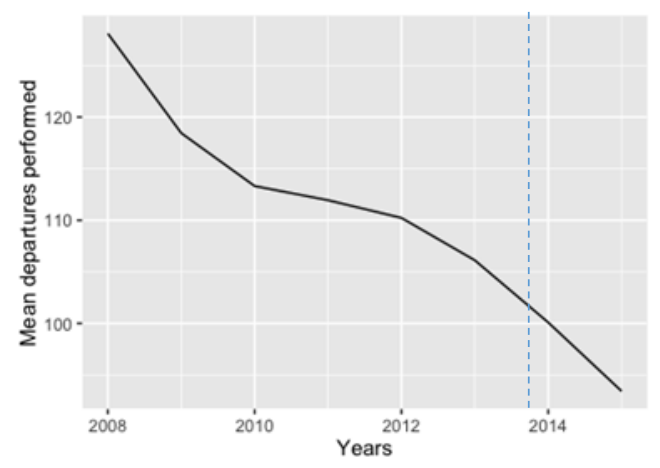

(a) Southwest and AirTran

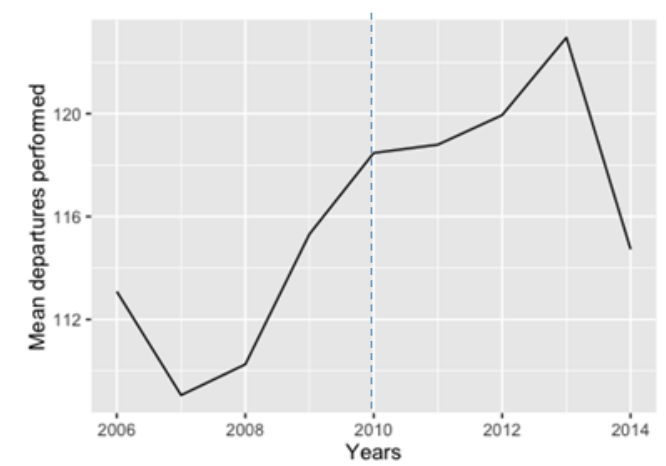

(c) Delta and Northwest

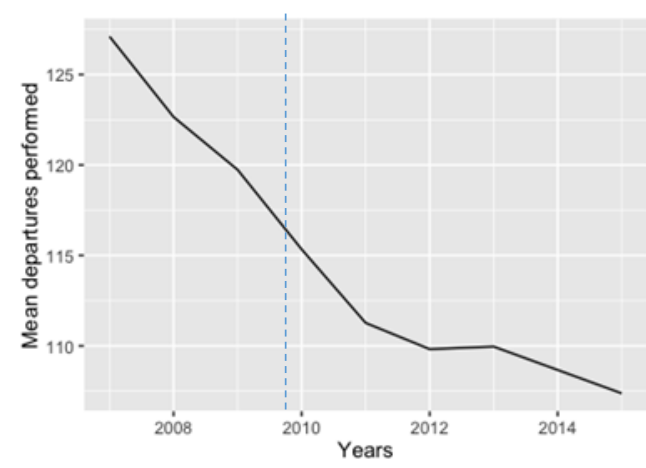

(b) United and Continental

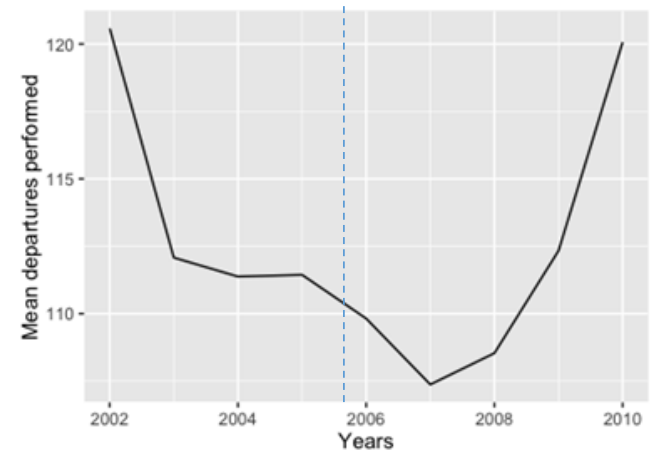

(d) US and America West

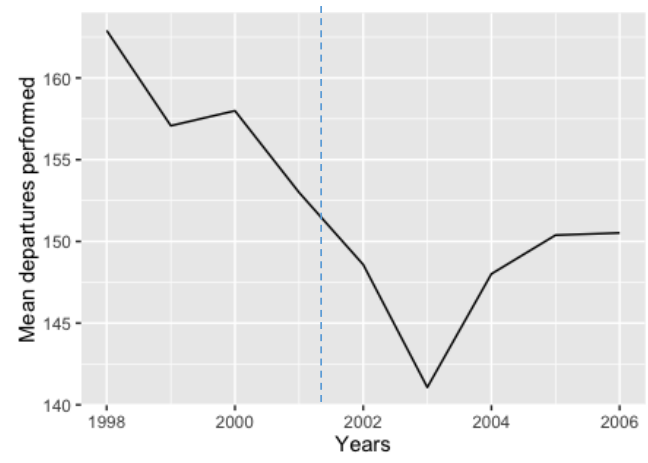

(e) American and Trans World

Note: The vertical dashed lines indicate the closing dates.

Table 3: Descriptive statistics

\begin{tabular}{lccccc}
\hline Variable & Observations & Mean & St. Dev. & Min. & Max. \\
\hline Frequency (number of departures per month) & 740659 & 104.8 & 89.0 & 20 & 1151 \\
Log of the frequency & 740659 & 4.36 & 0.77 & 3.00 & 7.05 \\
Merger02 dummy (the merger happened 0 to 2 years ago) & 740659 & 0.054 & 0.225 & 0 & 1 \\
Merger25 dummy (the merger happened 2 to 5 years ago) & 740659 & 0.055 & 0.229 & 0 & 1 \\
Route Herfindahl Index (HHI) on passengers & 740659 & 0.65 & 0.26 & 0.12 & 1.00 \\
Connections (which an airline has at the destination) & 740659 & 14.1 & 14.6 & 0 & 56 \\
Airline's route share & 740659 & 0.57 & 0.35 & 0.00 & 1.00 \\
Total number of seats of an airline on a route in a month & 740659 & 12672 & 13232 & 160 & 145480 \\
Total number of passengers of an airline on a route in a month & 740659 & 9432 & 10063 & 2 & 104713 \\
\hline
\end{tabular}


Our basic estimation (for airline $i$, origin $o$, destination $d$ and time period $t$ ) follows (and similarly when we use the logarithm of the frequency):

$$
\begin{aligned}
& \text { Frequency }_{\text {iodt }}= \beta_{1} \cdot \text { Merger } 02_{\text {it }}+\beta_{2} \cdot \text { Merger } 25_{i t} \\
&+\sum_{j=1999}^{j=2016} \alpha_{j} \cdot \text { Year }_{j}+\sum_{j=1999}^{j=2016} \alpha_{j, L C C} \cdot \text { Year }_{j} \cdot L C C_{i t}+\sum_{j=2}^{j=12} \gamma_{j} \cdot \text { month } \\
& j
\end{aligned}
$$

Frequency is measured by the number of departures of an airline $i$ in a particular month from an origin airport $o$ to a destination airport $d$. The Merger02 ${ }_{i t}$ dummy indicates if airline $i$ merged 0 to 2 years ago at time $t$; Merger $25_{\text {it }}$ is for a merger from 2 years to 5 years ago. This set-up follows Prince and Simon (2014) and allows us to differentiate the effect of mergers over the short run and the long run. The $\theta_{\text {iod }}$ are "carrier, origin airport and destination airport" specific fixed effects, of which there are 12508 distinct combinations. For example, flights from San Francisco International Airport to Los Angeles LAX have a different fixed effect from flights from Los Angeles to San Francisco. For an OD pair, the fixed effect also differs over the airlines. The coefficients $\alpha_{j}$ of the year dummies control for the year fixed effects. We also add additional year effects for low-cost carriers (LCCs), ${ }^{3}$ the coefficients $\alpha_{j, L C C}$ of which show how their frequency developments differ from those of the other carriers. Finally, we include month dummies to capture seasonality. ${ }^{4}$ The $\varepsilon_{\text {iod }}$ is the error term.

Our second estimation uses the same set-up as eq. 1, but the effects of the merger are differentiated between the five different cases. We will find that each merger seems to lower the frequency but that there are large differences between the five cases.

This raises the question of why this is the case. We argue that it could be due to differences in the market and/or network structure. The merger may alleviate serial marginalization if it allows for many new connections. On different routes the merger may also have different effects on the market structure and thereby on the price setting as well as on the quality setting (for a given price or number of passengers).

Although mergers can generate cost synergies, we hypothesize that the market power effect will dominate, leading to decreased frequencies overall. Weaker parallel competition lessens the effect of the merger as it affects the market less. If one of the merging airlines already had a monopoly on a route before the merger, we expect little effect of the merger on the market structure, whereas the cost saving may very well be the same as on other routes.

A merger between companies offering (potential) serial connecting routes may be relatively good for quality. Serial competition leads to very high prices and few passengers, and thus fewer flights. It may also lead to strategic undersupply of quality to limit the price competition (Czerny et al., 2016). ${ }^{5}$ So one would expect that, for a particular route, if the

\footnotetext{
${ }^{3}$ These are the airlines WN, NK, SY, F9, B6 and VX.

${ }^{4}$ It proved to be computationally impossible to include separate time effects for each month and year combination.

${ }^{5}$ If serial marginalization led to some potential connections not being used by any passengers, then the merger may make these attractive for some passengers, and this would potentially raise the frequency.
} 
destination has more connecting follow-up destinations offered by the merger airlines-be they pre-existing ones or ones added after the merger-this would be beneficial for the frequency on the route. To test this, we interact the merger dummies with the Connectionsiodt variable, which gives the number of follow-up connections at a destination at time $t$ for a (merged) airline. We also include the direct effect of the number of connections on the frequency. This could control for changes in economies of scale or scope following changes in the number of destinations. ${ }^{6}$ It could also control for changes in the attractiveness of a destination over time.

We use two different ways to test how the market structure between two airports alters the effect of a merger on the quality. The method of measuring the serial competition is the same in both set-ups.

The first method of including the market structure follows Borenstein (1990) and Chen and Gayle (2013). It differentiates the effects of mergers between the situation when both partners were flying between two airports and the situation when they were not. If only one partner was present before the merger, one would not expect to see an effect via the change in the market structure, while the quality may be affected by cost changes. Therefore, we hypothesize that, if both partners were present on a route, the merger should have the largest effect. Conversely, if one partner already had a monopoly between two airports—such that no other airlines were directly serving this route-the merger should not affect the market structure. Accordingly, in this case the impact of the merger on the quality may be limited, resulting only from cost changes and from indirect competition.

This leads to the following extensions of (1):

$$
\begin{aligned}
\text { Frequency }_{\text {iodt }}= & \text { Merger } 02_{\text {it }} \cdot\left(\beta_{1} \cdot \text { Both_Present }_{\text {iod }}+\beta_{2} \cdot \text { Monopoly }_{\text {iod }}+\beta_{3} \cdot \text { Other }_{\text {iod }}\right)+ \\
& \text { Merger } 25_{i t} \cdot\left(\beta_{4} \cdot \text { Both_Present }_{\text {iod }}+\beta_{5} \cdot \text { Monopoly }_{\text {iod }}+\beta_{6} \cdot \text { Other }_{\text {iod }}\right)+ \\
& +\beta_{7} \cdot \text { Merger } 02_{i t} \cdot \text { Connections }_{i t}+\beta_{8} \cdot{\text { Merger } 25_{i t} \cdot \text { Connections }_{\text {iodt }}}^{j=2016} \alpha_{j} \cdot \text { Year }_{j}+\sum_{j=1999}^{j=2016} \alpha_{j, L C C} \cdot \text { Year }_{j} \cdot \text { LCC }_{i t}+\sum_{j=2}^{j=12} \gamma_{j} \cdot \text { month }_{j}+\theta_{\text {iod }}+\varepsilon_{\text {iodt }} .
\end{aligned}
$$

Here the variable Both_Present ${ }_{i o d}$ is a dummy that takes the value one if both partners were flying from an origin to a destination in the eighteen months before the merger. The variable Monopoly $_{\text {iod }}$ is a dummy of which the value is one if one partner was the only one flying between two airports. The other rest category is predominantly for the situation when one partner faced competition from other airlines between the origin and the destination airport. The three categories are mutually exclusive, and they do not vary over time.

\footnotetext{
${ }^{6}$ Although for economies of scale we would expect more of an effect from the total number of flights at a destination than from the number of connections.
} 
The second method of including the route market structure follows Bilotkach et al. (2013). It measures the degree of competition using the Herfindahl-Hirschman Index (HHI) based on the number of passengers on a route in a month: ${ }^{7}$

$$
H H I_{\text {odt }}=\sum_{i=1}^{i=N_{\text {odt }}}(\text { Passenger_share } \text { iodt })^{2} \text {. }
$$

The HHI is a standard measure of the degree of competition (e.g., Borenstein, 1989). It is the same for all the airlines on a route, but it does vary over time. This leads to the following regression equation:

$$
\begin{aligned}
& \text { Frequency }_{\text {iodt }}=\beta_{1} \cdot{\text { Merger } 02_{i t}}+\beta_{2} \cdot \text { Merger } 25_{i t} \\
& +\beta_{3} \cdot \operatorname{Merger} 02_{i t} \cdot \operatorname{LAG}\left[\mathrm{HHI}_{\text {odt }}\right]+\beta_{4} \cdot \operatorname{Merger}^{2} 5_{i t} \cdot \mathrm{LAG}\left[\mathrm{HHI} \mathrm{Idt}_{\text {odt }}\right]
\end{aligned}
$$

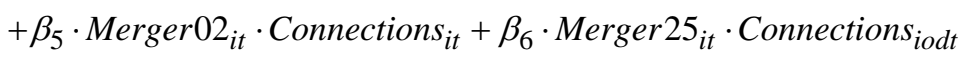

$$
\begin{aligned}
& +\beta_{6} \cdot \mathrm{LAG}\left[\mathrm{HHI}_{\text {odt }}\right]+\beta_{7} \cdot \text { Connections }_{\text {iodt }} \\
& +\sum_{j=1999}^{j=2016} \alpha_{j} \cdot \text { Year }_{j}+\sum_{j=1999}^{j=2016} \alpha_{j, L C C} \cdot \text { Year }_{j} \cdot \text { LCC }_{i t}+\sum_{j=2}^{j=12} \gamma_{j} \cdot \text { month }_{j}+\theta_{\text {iod }}+\varepsilon_{\text {iodt }} \text {. }
\end{aligned}
$$

An issue is that the HHI partly depends on the number of flights, as more flights allow for more passengers. Following Bilotkach et al. (2013), we deal with this problem by lagging the HHI by 12 months. Our heavy use of fixed effects makes it difficult to argue that lagged shocks in the concentration of passengers are affected by current shocks to the current number of departures. The identification in fixed-effect estimations is based on the deviations from the mean of a group. The number of connections offered is a long run decision, so (a shock to) the current frequency does not affect the number of connections. Accordingly, the number of connections should be exogenous.

A final concern is that mergers may be endogenous, as firms with more to gain from a merger in cost savings, pricing or quality improvements may be more likely to merge. Again, this issue should be limited by our heavy use of fixed effects.

\section{Base regressions}

\subsection{Regressions}

Table 4 presents the coefficients of interest for our panel regression of eq. (1); Table A.1 in the appendix provides the full results. ${ }^{8}$ The table shows the outcome when the monthly frequency is the dependent variable and when its logarithm is the dependent variable. In all our estimations, we cluster our standard errors on the combination of carrier, origin airport and destination airport. This allows for remaining serial correlation and heteroskedasticity.

\footnotetext{
${ }^{7} N_{\text {odt }}$ is the number of airlines flying from orgin $o$ to destination $d$ in time period $t$.

${ }^{8}$ The full results show that, all else being equal, the numbers of flights of airlines have decreased over time. However, this decrease is smaller for the LCCs. The seasonal pattern over the months seems to be as we would expect: for example, fewer flights in the winter.
} 
We differentiate the effect of the merger dummy in the short run (0 until 2 years after the merger) and the long run (from 2 to 5 years). We find strong support for the hypothesis that mergers decrease the monthly frequency, and more in the long run than in the short run. In the period 0 to 2 years after the merger, on average the monthly frequency of the merged airlines between two airports decreases by 9.51. For 2 to 5 years after the merger, the average decrease is 12.03. Following the log frequency specification of Table 4, a merger leads to a $100 \cdot(\operatorname{Exp}(-0.091)-1)=-8.7 \%$ change in the monthly frequency in the first 2 years and to a 12.2\% reduction in the long run (Halvorsen and Palmquist, 1980). Accordingly, both specifications indicate that mergers lower the quality of service of the merging airlines and that the effect is stronger in the long run.

Table 4: Base regression

\begin{tabular}{|c|c|c|c|c|c|}
\hline & & \multicolumn{2}{|c|}{ Frequency } & \multicolumn{2}{|c|}{ Log frequency } \\
\hline & & Coef. & T-stat. & Coef. & T-stat. \\
\hline \multirow{3}{*}{ Merger } & $0-2$ years & $-9.51^{* * *}$ & -8.68 & $-0.091^{* * *}$ & -7.50 \\
\hline & $2-5$ years & $-12.03^{* * *}$ & -9.96 & $-0.130^{* * *}$ & -8.59 \\
\hline & & \multicolumn{2}{|c|}{$\mathrm{R}^{2}: 0.100^{\#}$} & \multicolumn{2}{|c|}{$\mathrm{R}^{2}: 0.078^{\#}$} \\
\hline
\end{tabular}

Notes: ${ }^{\#}$ The $\mathrm{R}^{2}$ is the within $\mathrm{R}^{2}$ of the part of the variance of the demeaned data that is explained by the model. Significance levels: ${ }^{*}$

indicates significance at the $5 \%,{ }^{* *}$ at the $1 \%$ and ${ }^{* * *}$ at the $0.1 \%$ level. The standard errors are clustered on the OD pair and carrier combination. Also included but not shown here are 12508 fixed effects on the combination of airline, origin airport and destination airport as well as year fixed effects for regular and low-cost carriers and month fixed effects.

Table 5 reports the results when we differentiate the effects of the five mergers. All the merger dummies have negative coefficients and most are significantly so. This again indicates the negative impact of mergers on the frequency. The table shows large differences between the effects of the five mergers. The merger that stands out is between United and Continental. Following the log frequency regression, this merger lowered the monthly frequency on a route by $21.6 \%{ }^{9}$ in the short run and by $32 \%$ in the long run. Conversely, in the short run, both the SouthWest and AirTran merger ${ }^{10}$ and the American and Trans World merger led to a decrease of less than 2\%, the Delta and NorthWest merger led to a $7.6 \%$ decrease, and the US and America West merger resulted in a 7\% decrease. For the last three of these mergers, the short run and long run effects are similar. Therefore, the finding in Table 4 that the long run effect is stronger than the short run effect seems predominantly to be due to the merger of United and Continental.

To conclude, Table 5 indicates that mergers lower the frequency of the merged airlines. However, there are large differences between the five mergers. The merger between United and Continental led to the largest decrease, and the effect is even larger in the long run than in the short run. For the other mergers, the effects are smaller and the differences between the short run and the long run seem to be limited.

$\left.{ }^{9}-100 \% \cdot \operatorname{Exp}(-0.243)-1\right)=21.6 \%$

${ }^{10}$ This SouthWest (WN) and AirTran (FL) merger is relatively recent, so we could not estimate the long run effect. 
Table 5: The merger effect differentiated between the five mergers

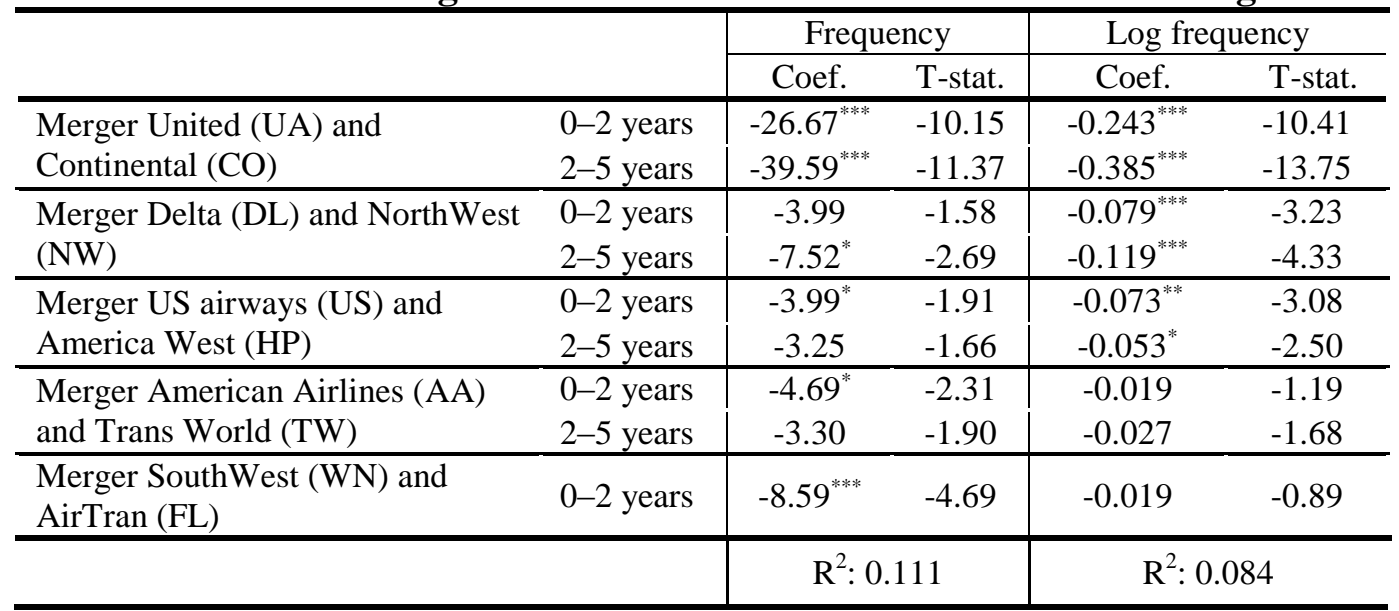

Notes: ${ }^{\#}$ The $\mathrm{R}^{2}$ is the within $\mathrm{R}^{2}$ of the part of the variance of the demeaned data that is explained by the model. Significance levels: * indicates significance at the $5 \%,{ }^{* *}$ at the $1 \%$ and ${ }^{* * *}$ at the $0.1 \%$ level. The standard errors are clustered on the OD pair and carrier combination. Also included but not shown here are fixed effects on the combination of airline, origin airport and destination airport as well as year fixed effects for regular and low-cost carriers and month fixed effects.

\subsection{Sensitivity analyses}

We now turn to a number of sensitivity analyses. Using these, we try to establish the robustness of our results.

For Tables 4 and 5, we keep feeder airlines separate from their parent companies. For example, American Eagle is a feeder airline for American Airlines. These feeders could be seen as being part of their parents. Table A. 2 tests the effects of this by showing a regression for the frequency after adding all the flights of feeders to their parents. ${ }^{11}$ This change to the dataset has little effect on the results.

Table A.2 also adds ultra-short run effects. It adds dummies for the period 3 months before the merger and 3 months after it. The coefficients for the 0-2-year and 2-5-year effects of mergers stay roughly the same as in Table 5. For the United and Continental case and the SouthWest and AirTran case, in the 3 months before the merger, we can already see a significant decrease in the frequency. For the other three mergers, there are no significant effects. During the 3 months after the merger, in the United and Continental case and the SouthWest and AirTran case, an even larger frequency decrease is apparent than in the period 3 months to 2 years after the merger. For American and Trans World, there is an increase in frequency in the 3 months after the merger, followed by a decrease. The most important outcome is that our results seem to be robust to allowing for ultra-short run disturbances following mergers.

Different from our results, Prince and Simon (2014) find a less negative and mostly insignificant effect of mergers on the frequency, even though they also use data from the Department of Transportation and an almost methodology. Plausible sources of this difference are their smaller dataset, their shorter time span of the data and their use of the delays (OTP)

\footnotetext{
${ }^{11}$ We use Table 2 of Chen and Gayle (2013) to identify the feeders.
} 
dataset that focuses on large airlines and while we use the T100 dataset that contains all US airlines. Our monthly dataset has 740659 observations. Their one-day-for-each-month dataset has 346901 observations, and their quarterly dataset has 133870 observations.

\section{How do the market and network structures affect the impact of mergers?}

To test if the market and network structures alter how mergers affect the quality setting, we use eqs. (2) and (3). Both specifications allow the possibility that the effect of the merger will be more beneficial on routes where the destination has more potential connections. Both also differentiate the effect of the merger between the short run of $0-2$ years and the long run of 25 years. Specification (3) allows the effect of a merger to change with the degree of market power on a route by interacting the merger dummies with the lagged HHI. Specification (2) allows the possibility that the effect of a merger will be different if both partners were present on a route before the merger or if one partner had a monopoly. These dummy indicators are for the period 18 months before the merger, and unlike the HHI they do not vary over time.

\subsection{Market and network structures and the effect of mergers}

Table 6 presents the results of the regression of eq. (3). It focuses on the important variables; the full results are in Table A.3. Our Herfindahl-Hirschman Index (HHI) is based on the number of passengers. It is a measure of the degree of competition: an HHI of 1 means a monopoly, while an $\mathrm{HHI}$ of 0 means perfect competition with infinitesimally small firms. We lag the HHI by 12 months. This, together with the heavy use of fixed effects, should prevent issues with endogeneity. The table again shows that the effect of a merger is more negative in the long run than in the short run.

Table 6: Do the effects of mergers depend on the market structure and the number of connections?

\begin{tabular}{|c|c|c|c|c|c|c|}
\hline & & & \multicolumn{2}{|c|}{ Frequency } & \multicolumn{2}{|c|}{ Log frequency } \\
\hline & & & Coef. & T-stat. & Coef. & T-stat. \\
\hline \multirow{6}{*}{ Merger } & & $0-2$ years & $-20.81^{* * *}$ & 7.02 & $-0.194^{* * *}$ & -7.50 \\
\hline & & 2-5 years & $-31.76^{* * *}$ & 8.80 & $-0.261^{* * *}$ & -8.59 \\
\hline & \multirow{2}{*}{ Lagged HHI } & $0-2$ years & $20.44^{* * *}$ & 6.06 & $0.171^{* * *}$ & 5.82 \\
\hline & & 2-5 years & $34.87^{* * *}$ & 7.71 & $0.231^{* * *}$ & 6.07 \\
\hline & \multirow{2}{*}{ Connections } & $0-2$ years & 0.03 & 0.63 & $0.001^{* *}$ & 2.62 \\
\hline & & 2-5 years & $0.20^{* * *}$ & 3.23 & $0.003^{* * *}$ & 5.41 \\
\hline Lagged HHI & & & $22.99^{* * *}$ & 10.07 & $0.248^{* * *}$ & 11.91 \\
\hline \multirow[t]{2}{*}{ Connections } & & & $1.74^{* * *}$ & 15.60 & $0.018^{* * *}$ & 19.69 \\
\hline & & & \multicolumn{2}{|c|}{$\mathrm{R}^{2}=0.160$} & \multicolumn{2}{|c|}{$\mathrm{R}^{2}=0.138$} \\
\hline
\end{tabular}

Note: The $\mathrm{R}^{2}$ is the within $\mathrm{R}^{2}$ of the part of the variance of the demeaned data that is explained by the model. Significance levels: ${ }^{*}$ indicates significance at the $5 \%,{ }^{* *}$ at the $1 \%$ and ${ }^{* * *}$ at the $0.1 \%$ level. The standard errors are clustered on the OD pair and carrier combination. Fixed effects on 12508 airline-OD combinations, as well as on year, LCC*year and month, are included but are not shown here; see Table A.3.

On a competitive route, which has an HHI close to 0, a merger significantly lowers the frequency of the merged airlines. On routes with little competition, a merger does not significantly affect the frequency: the effect can be slightly negative or slightly positive 
depending on the specification and the values of the interaction variables. Consistent with our hypothesis, on routes with more parallel competition a merger seems to be more detrimental to the frequency.

In the frequency regression, in the short run, the number of connections does little to alter the effect of the merger; in the long run, there is the significant result that more connections make a merger better for the frequency. In the log frequency regression, the effect via the number of connections is always significant. This is mostly consistent with our hypothesis, as it predicted that, for a destination with connections of the merged airlines, a merger is more positive for the frequency of those airlines.

\subsection{Pre-existing market structure and the effects of mergers}

In the previous section, we used the time-varying HHI to measure the market structure. Now we will use three dummies for the pre-existing market structure that are mutually exclusive: 1) if both partners were flying between two airports in the eighteen months before the merger, 2) if one partner had a monopoly and 3) the rest category that almost wholly consists of one partner being on a route and facing some competition. ${ }^{12}$

Again, we also control for the number of connections and how it changes the effect of mergers on quality. The coefficients for the number of the connections interacted with the merger dummies stay virtually identical. Therefore, this effect seems to be robust.

The three options for the market structure are mutually exclusive. If only one partner was flying between two airports and faced competition, the merger still lowers the frequency. This is even though the merger does not directly affect the market structure between the two airports, although the merger might affect the competition via hubbing indirect routes. For zero to two years since the merger, if one partner had a monopoly, the results are as expected: the coefficient in both the frequency and the log frequency is tiny and insignificant. Somewhat surprisingly, in the long run, the effect is more substantial, negative and highly significant in the log frequency case. This suggests that a merger may reduce the frequency in the long run even if there was already a monopoly on a route.

If both partners were present on a route, the results of the merger are mixed and not entirely consistent with our hypotheses. In the log frequency specification, the merger seems to raise the frequency, which contradicts our predictions. In the frequency specification, there is no significant effect of the merger in this case. In the short run, the coefficient is very negative, with -27.07 . In the long run, the coefficient is positive again and insignificant.

To conclude, our empirical findings on how the network structure alters the effect of mergers on the frequency setting is consistent with our hypothesis: more connections at a destination mean that the merger is less harmful. The results for the market structure are

\footnotetext{
12 There are a few cases in which the second merging partner was present on a route for a few months of the 18-month period before the merger, but adding these to the group in which both partners were present only makes the estimation less precise and has very little effect on the coefficients.
} 
mixed. If one partner had a monopoly, there seems to be little effect in the short run from the merger on the frequency and possibly a negative one in the long run. The results for the effect of a merger when both partners were flying between two airports are inconclusive. This may be because it is rare for two merger partners both to fly between two airports directly; much of the competition will be via hubbing routes that offer an indirect service. However, a measure of indirect competition is not available in our dataset.

Table 7: Does the effect of mergers change if both partners were present on a route or if a partner had a monopoly?

\begin{tabular}{|c|c|c|c|c|c|c|}
\hline & & & \multicolumn{2}{|c|}{ Frequency } & \multicolumn{2}{|c|}{ Log frequency } \\
\hline & & & Coef. & T-stat. & Coef. & T-stat. \\
\hline \multirow{8}{*}{ Merger } & \multirow{2}{*}{$\begin{array}{l}\text { One partner was on a } \\
\text { route with competition }\end{array}$} & $0-2$ years & $-11.42^{* * *}$ & -7.04 & $-0.124^{* * *}$ & -8.12 \\
\hline & & 2-5 years & $-15.65^{* * *}$ & -8.22 & $-0.165^{* * *}$ & -9.19 \\
\hline & \multirow{2}{*}{$\begin{array}{l}\text { Both partners were on } \\
\text { a route }\end{array}$} & $0-2$ years & -27.07 & -1.76 & $0.098^{*}$ & 2.42 \\
\hline & & 2-5 years & 4.84 & 0.17 & $0.240^{* * *}$ & 3.13 \\
\hline & \multirow{2}{*}{$\begin{array}{l}\text { One partner had a } \\
\text { monopoly }\end{array}$} & $0-2$ years & 0.74 & 0.45 & -0.009 & -0.54 \\
\hline & & 2-5 years & -1.81 & -0.88 & $-0.082^{* * *}$ & -3.78 \\
\hline & \multirow{2}{*}{ Connections } & $0-2$ years & 0.02 & 0.45 & $0.001^{*}$ & 2.13 \\
\hline & & 2-5 years & $0.23^{* * *}$ & 3.64 & $0.003^{* * *}$ & 5.46 \\
\hline \multirow{2}{*}{\multicolumn{3}{|c|}{ Connections }} & $1.86^{* * * *}$ & 18.52 & 0.020 & 23.50 \\
\hline & & & \multicolumn{2}{|c|}{$\mathrm{R}^{2}=0.134$} & \multicolumn{2}{|c|}{$\mathrm{R}^{2}=0.111$} \\
\hline
\end{tabular}

Notes: " The $\mathrm{R}^{2}$ is the within $\mathrm{R}^{2}$ of the part of the variance of the demeaned data that is explained by the model. Significance levels: ${ }^{*}$ indicates significance at the $5 \%,{ }^{* *}$ at the $1 \%$ and ${ }^{* * *}$ at the $0.1 \%$ level. The standard errors are clustered on the OD pair and carrier combination. Fixed effects on airline-OD combinations, as well as on year, LCC*year and month, are included but are not shown here.

\subsection{Sensitivity analyses}

Now we again test how robust our results. We first investigate the effect of the lag of the HHI, which we lagged 12 months to deal with potential endogeneity. See Table A.4 in the appendix. Removing the lag has little impact on the results, although the effects of the HHI directly and via the merger dummies become a little stronger. This suggests that the heavy use of fixed effects may already have solved most of the possible endogeneity issue. As a second check, in the third column, we use a different HHI based on the number of flights instead of the number of passengers. This change also does not particularly alter the estimation. ${ }^{13}$

Thereafter, we look at the effects of alternative ways to measure the parallel market structure. In Table 6 we noticed that the effect of merging on the frequency is about zero if the merged airlines have a monopoly. This raises the following question: is this purely an effect of a monopoly or do weakly competitive settings lead to similar results? Table A.5 tests this by adding interactions of the merger dummies with a lagged monopoly dummy that measures whether the merged airlines have a monopoly on a route at a particular moment in time. The effects of mergers remain roughly the same, although the effects are stronger and the

\footnotetext{
${ }^{13}$ We also tried differentiating the effects over the years, as the effect of mergers may have changed over time. If this is the case, then our results may be biased. To test this, we interacted the HHI and its interactions with the merger dummies with a continuous time variable. The coefficients of the HHI interacted with the merger dummies stay roughly the same. So again the effects seem to be robust.
} 
interactions of the merger dummies with the monopoly dummy have significantly negative effects. This again suggests that a merger tends to lower the frequency of the merged airlines if a route is competitive. A merger may even raise the frequency if the route is weakly competitive, although the net effect is not significantly different from zero. In the third estimation of Table A.5, we replace the lagged HHI of the route with the one-year-lagged share of the merged airlines. The results are quantitatively the same as in the main estimation. A merger tends to lower the frequency on a route if the merged airlines have a small share, while it has little effect if the merged airlines have a large share.

Finally, we check if the effects of the market and network structures remain if we also differentiate the effect of the merger between the five different mergers. Table A.6 in the appendix shows the extensions of the estimation of Table 6. Table A.7 does this for Table 7. The effects of the network and market structures remain roughly the same. The coefficients for the five different mergers are more similar over the cases than in Table 5. The market and network structures indeed explain part of the difference in the effects of the five mergers. Nevertheless, the five cases still seem to have different effects on the frequency. In particular, the merger between United and Continental has a significantly more negative effect than the other four. To conclude, all this suggests that the network and market structures explain part but not all of the variation in the effects of the five mergers.

\section{Conclusion}

We investigated the effects of five US airline mergers on one quality dimension, namely the frequency of flying. Passengers care about the frequency: a higher frequency means on the whole that they can depart closer to their preferred time of departure. On average, the mergers decreased the frequency and thus the quality. This effect seems to be stronger in the long run than in the short run. However, we found large differences in the effects of the five mergers. We hypothesized that it is due to differences in the market and network structures. We indeed found that a less competitive route and more serial follow-up connections at the destination make the merger less detrimental to the frequency. If one of the merging parties had a monopoly between two airports, the merger had no direct effect on the market structure. We found that in such cases the effect of the merger on the frequency was tiny in the short run, although it was more negative in the long run. We expected that a merger would be most harmful to the frequency when both partners were present on a route before the merger, but this did not prove to be true, and, in the log frequency specification, a merger actually was positive for the frequency in this case.

It hence seems that the market and network structures explain part of the difference in the effects of the five mergers, but there remain unexplained further reasons for these differences. This seems to be a topic worthy of further investigation. It may just be that the five mergers had very different effects on costs and in particular on the marginal costs of quality. However, 
there may also be effects from indirect competition via hubbing airports or from potential entry, for which we cannot allow using our T-100 dataset. It also seems worthwhile to study other dimensions of quality. For instance, Prince and Simon (2012) found that airline mergers may slightly worsen travel times in the short run, while travel times may remain unchanged or even decrease in the long run. They argued that this is due to cost synergies. Chen and Gayle (2013) found that one merger lowered the routing quality while another raised the routing quality, where the routing quality is measured by the non-stop flight distance divided by the actual flight distance. Accordingly, not only may different mergers have different effects on a quality dimension but also their effects may differ over the different dimensions of quality.

\section{Acknowledgements}

This research is partly based on the master thesis of Rijken (2016). We thank the participants of the Eureka seminar in Amsterdam. We appreciate the comments of Thomas de Graaff, Jos van Ommeren and Christiaan Behrens. Any remaining errors are ours. This research does not necessarily represent the views of our employers. 


\section{Appendix}

Table A.1: Full results base regression of Table 3 in text

\begin{tabular}{|c|c|c|c|c|}
\hline & \multicolumn{2}{|c|}{ Frequency } & \multicolumn{2}{|c|}{ Log Frequency } \\
\hline & Coef. & T-stat & Coef. & T-stat \\
\hline $0-2$ years & -9.51 & -8.68 & -0.091 & -9.1 \\
\hline Merger & -12.03 & -9.96 & -0.130 & -11.9 \\
\hline \multicolumn{5}{|l|}{ year } \\
\hline 1999 & 1.40 & 2.87 & 0.020 & 4.90 \\
\hline 2000 & 0.63 & 0.84 & 0.025 & 4.00 \\
\hline 2001 & -3.62 & -4.22 & -0.004 & -0.50 \\
\hline 2002 & -10.42 & -9.89 & -0.046 & -5.40 \\
\hline 2003 & -17.92 & -14.36 & -0.113 & -11.10 \\
\hline 2004 & -15.37 & -11.41 & -0.101 & -8.80 \\
\hline 2005 & -18.60 & -13.03 & -0.126 & -10.30 \\
\hline 2006 & -22.11 & -14.65 & -0.156 & -11.90 \\
\hline 2007 & -26.55 & -17.27 & -0.202 & -15.30 \\
\hline 2008 & -31.09 & -19.37 & -0.251 & -18.50 \\
\hline 2009 & -32.58 & -19.06 & -0.252 & -18.00 \\
\hline 2010 & -31.99 & -17.53 & -0.256 & -17.50 \\
\hline 2011 & -34.60 & -18.70 & -0.292 & -19.50 \\
\hline 2012 & -33.28 & -17.52 & -0.275 & -18.00 \\
\hline 2013 & -32.03 & -16.33 & -0.266 & -17.20 \\
\hline 2014 & -35.22 & -18.13 & -0.300 & -19.40 \\
\hline 2015 & -42.26 & -21.50 & -0.364 & -23.30 \\
\hline 2016 & -46.97 & -22.43 & -0.408 & -23.50 \\
\hline \multicolumn{5}{|l|}{ Month effects } \\
\hline Feb & -9.12 & -69.92 & -0.087 & -83.40 \\
\hline March & 5.08 & 42.70 & 0.051 & 37.20 \\
\hline Apr & 2.19 & 17.50 & 0.022 & 15.00 \\
\hline May & 5.91 & 38.60 & 0.058 & 34.40 \\
\hline Jun & 3.76 & 20.94 & 0.037 & 18.80 \\
\hline Jul & 8.34 & 39.26 & 0.083 & 38.80 \\
\hline Aug & 7.94 & 37.33 & 0.075 & 36.40 \\
\hline Sep & -0.47 & -2.66 & -0.003 & -1.50 \\
\hline Oct & 5.53 & 31.67 & 0.055 & 30.20 \\
\hline Nov & -0.84 & -5.82 & -0.004 & -2.50 \\
\hline Dec & -0.76 & -5.56 & 0.001 & 1.00 \\
\hline LLC $\cdot 1999$ & -3.57 & -2.99 & -0.019 & -1.60 \\
\hline $\mathrm{LLC} \cdot 2000$ & -3.99 & -2.32 & -0.017 & -1.10 \\
\hline LLC $\cdot 2001$ & -2.71 & -1.25 & -0.023 & -1.30 \\
\hline $\mathrm{LLC} \cdot 2002$ & 1.89 & 0.71 & 0.015 & 0.80 \\
\hline $\mathrm{LLC} \cdot 2003$ & 9.05 & 3.08 & 0.093 & 4.30 \\
\hline $\mathrm{LLC} \cdot 2004$ & 11.04 & 3.54 & 0.128 & 5.50 \\
\hline $\mathrm{LLC} \cdot 2005$ & 17.68 & 5.10 & 0.199 & 8.10 \\
\hline $\mathrm{LLC} \cdot 2006$ & 23.88 & 6.25 & 0.269 & 10.00 \\
\hline LLC $\cdot 2007$ & 29.85 & 7.77 & 0.331 & 12.30 \\
\hline $\mathrm{LLC} \cdot 2008$ & 29.55 & 7.53 & 0.345 & 12.60 \\
\hline $\mathrm{LLC} \cdot 2009$ & 21.46 & 5.29 & 0.268 & 9.60 \\
\hline $\mathrm{LLC} \cdot 2010$ & 17.23 & 4.11 & 0.248 & 8.60 \\
\hline $\mathrm{LLC} \cdot 2011$ & 20.56 & 4.81 & 0.308 & 10.50 \\
\hline LLC $\cdot 2012$ & 19.20 & 4.42 & 0.290 & 9.90 \\
\hline $\mathrm{LLC} \cdot 2013$ & 15.65 & 3.57 & 0.265 & 9.00 \\
\hline $\mathrm{LLC} \cdot 2014$ & 15.57 & 3.53 & 0.275 & 9.30 \\
\hline $\mathrm{LLC} \cdot 2015$ & 26.79 & 5.97 & 0.379 & 12.30 \\
\hline LLC $\cdot 2016$ & 29.99 & 6.58 & 0.402 & 12.60 \\
\hline
\end{tabular}

Note: also included but not shown here are fixed effects on the combination of airline, origin airport and destination airport. 
Table A.2: Monthly frequency: base regression vs integrated feeders and separate effect 3-0 months before the merger and 0-3 months before

\begin{tabular}{|c|c|c|c|c|c|}
\hline & & \multicolumn{2}{|c|}{ Base regression } & \multicolumn{2}{|c|}{$\begin{array}{l}\text { Integrated feeders and separate } \\
\text { ultra-short-run effects }\end{array}$} \\
\hline & & Coef. & T-stat & Coef. & T-stat \\
\hline \multirow{2}{*}{ Merger United (UA) and Continental (CO) } & 0 -2 years & $-26.67^{* * *}$ & -10.15 & $-23.26^{* * *}$ & -9.96 \\
\hline & $2-5$ years & $-39.59^{* * *}$ & -11.37 & $-32.38^{* * *}$ & -10.3 \\
\hline \multirow{2}{*}{ Merger Delta (DL) and NorthWest (NW) } & 0 -2 years & -3.99 & -1.58 & -2.24 & -1.14 \\
\hline & $2-5$ years & $-7.52^{*}$ & -2.69 & $-4.79^{*}$ & -2.28 \\
\hline \multirow{2}{*}{$\begin{array}{l}\text { Merger US airways (US) and America West } \\
\text { (HP) }\end{array}$} & $0-2$ years & $-3.99^{*}$ & -1.91 & $-5.14^{*}$ & -2.28 \\
\hline & $2-5$ years & $-3.25^{\dagger}$ & -1.66 & -3.15 & -1.60 \\
\hline \multirow{2}{*}{$\begin{array}{l}\text { Merger American Airlines (AA) and Trans } \\
\text { World (TW) }\end{array}$} & $0-2$ years & $-4.69^{*}$ & -2.31 & $-8.25^{* * *}$ & -4.03 \\
\hline & $2-5$ years & -3.30 & -1.90 & -1.05 & -0.64 \\
\hline Merger SouthWest (WN) and AirTran (FL) & 0 -2 years & $-8.59^{* * *}$ & -4.69 & $-7.73^{* * *}$ & -4.13 \\
\hline \multirow{2}{*}{ Merger United (UA) and Continental (CO) } & 3 months before & & & $-5.91^{* * * *}$ & -3.45 \\
\hline & 3 months after & & & $-4.58^{* *}$ & -2.70 \\
\hline \multirow{2}{*}{ Merger Delta (DL) and NorthWest (NW) } & 3 months before & & & 1.54 & 0.91 \\
\hline & 3 months after & & & -0.46 & -0.35 \\
\hline \multirow{2}{*}{$\begin{array}{l}\text { Merger US airways (US) and America West } \\
\text { (HP) }\end{array}$} & 3 months before & & & -1.86 & -0.99 \\
\hline & 3 months after & & & $3.81^{*}$ & 2.37 \\
\hline \multirow{2}{*}{$\begin{array}{l}\text { Merger American Airlines (AA) and Trans } \\
\text { World (TW) }\end{array}$} & 3 months before & & & 3.75 & 1.45 \\
\hline & 3 months after & & & $16.30^{* * *}$ & 10.0 \\
\hline \multirow{3}{*}{ Merger SouthWest (WN) and AirTran (FL) } & 3 months before & & & $-3.55^{* * *}$ & -4.89 \\
\hline & 3 months after & & & $-4.78^{* * *}$ & -9.64 \\
\hline & & \multicolumn{2}{|c|}{$\mathrm{R}^{2}: 0.111$} & \multicolumn{2}{|c|}{$\mathrm{R}^{2}: 0.084$} \\
\hline
\end{tabular}

Note: for three months after the merger, both the Merger_3_months_after and the Merger_0_to_2_years dummies are 1. So the 3 months after coefficient measures the ultra short-run effect on top on the short-run effect. Hence, in the 3 months after the UA and CO merger the frequency was $23.26+4.58=29.17$ lower.

Significance levels: ${ }^{*}$ indicates significance at the $5 \%,{ }^{* *}$ at the $1 \%$ and ${ }^{* * *}$ at the $0.1 \%$ level. The standard errors are clustered on the OD pair and carrier combination. Fixed effects on airline-OD combinations, on year, on LCC*year and on month are included but are not shown. 
Table A.3: Full results for the regression of Table 6 in text

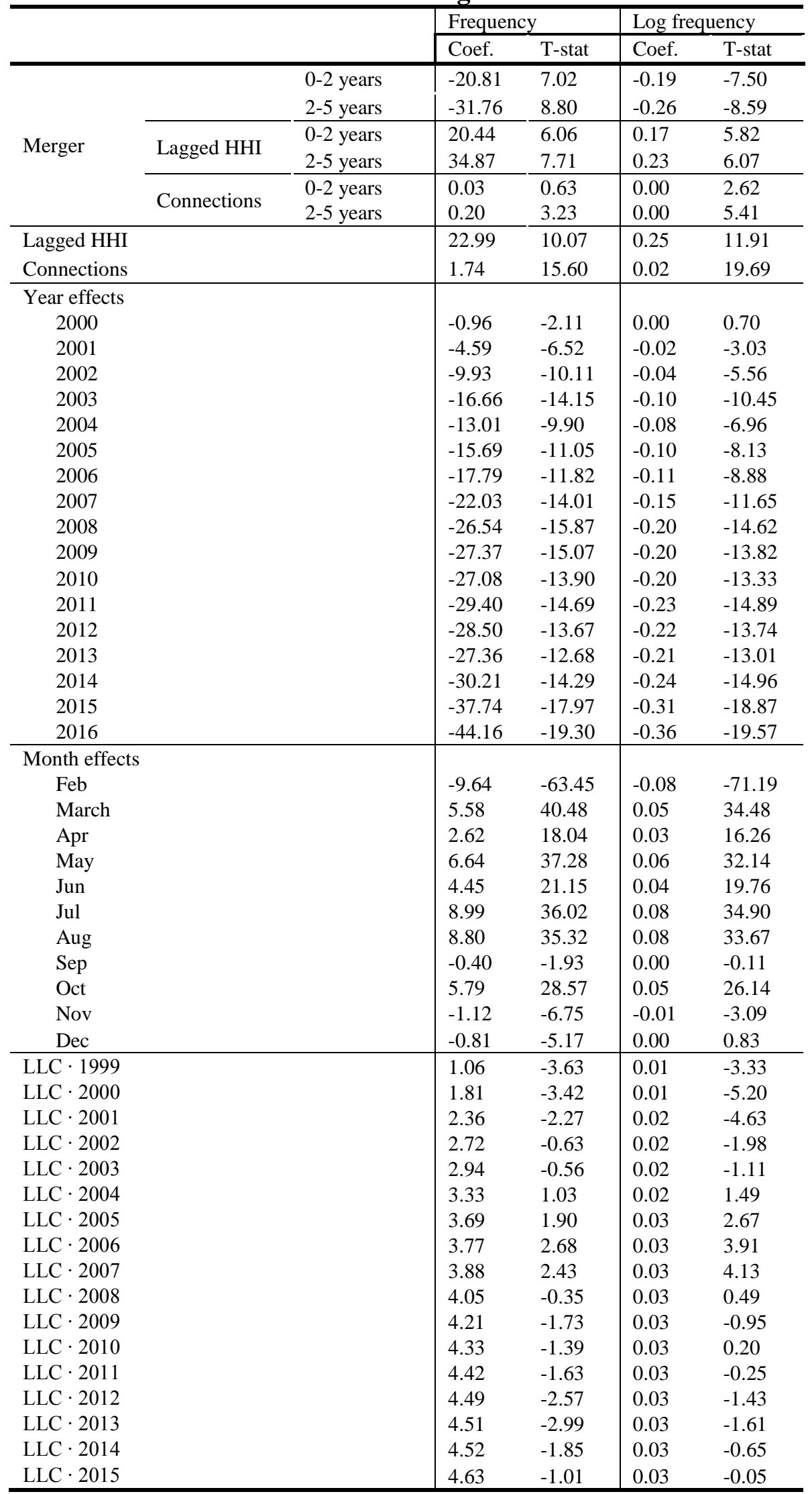


Table A.4: Sensitivity analyses for the HHI set-up for the regression of Table 6

\begin{tabular}{|c|c|c|c|c|c|c|c|c|}
\hline & & & \multicolumn{2}{|c|}{ 1: Final regression } & \multicolumn{2}{|c|}{ 2: No lags } & \multicolumn{2}{|c|}{ 3: HHI on flights } \\
\hline & & & Coef. & T-stat & Coef. & T-stat & Coef. & T-stat \\
\hline \multirow{6}{*}{ Merger } & & $0-2$ years & $-20.81^{* * *}$ & -7.02 & $-21.01^{* * *}$ & -7.52 & $-19.32^{* *}$ & -2.78 \\
\hline & & 2-5 years & $-31.76^{* * *}$ & -8.80 & $-35.05^{* * *}$ & -9.98 & $-28.59^{* * *}$ & -3.38 \\
\hline & \multirow{2}{*}{ HHI } & $0-2$ years & $20.44^{* * *}$ & 6.06 & $22.22^{* * *}$ & 6.89 & $18.92^{* * *}$ & 3.16 \\
\hline & & 2-5 years & $34.87^{* * * *}$ & 7.71 & $40.64^{* * * *}$ & 9.14 & $31.04^{* * *}$ & 4.25 \\
\hline & \multirow{2}{*}{ Connections } & $0-2$ years & 0.03 & 0.63 & 0.02 & 0.35 & 0.03 & 0.05 \\
\hline & & 2-5 years & $0.20^{* * *}$ & 3.23 & $0.18^{* *}$ & 2.97 & 0.21 & 0.06 \\
\hline HHI & & & $22.99^{* * *}$ & 10.07 & $39.50^{* * *}$ & 17.91 & $23.70^{*}$ & 2.08 \\
\hline \multirow[t]{2}{*}{ Connections } & & & $1.74^{* * * *}$ & 15.60 & $1.76^{* * *}$ & 17.85 & 1.73 & 0.11 \\
\hline & & & \multicolumn{2}{|c|}{$\mathrm{R}^{2}=0.160$} & \multicolumn{2}{|c|}{$\mathrm{R}^{2}=0.159$} & \multicolumn{2}{|c|}{$\mathrm{R}^{2}=0.159$} \\
\hline
\end{tabular}

Note: significance levels: ${ }^{*}$ indicates significance at the $5 \%,{ }^{* *}$ at the $1 \%$ and ${ }^{* * *}$ at the $0.1 \%$ level. The standard errors are clustered on the OD pair and carrier combination. Fixed effects on airline-OD combinations, on year, on LCC*year and on month are included but are not shown.

Table A.5: Further sensitivity analyses for the regression of Table 6

\begin{tabular}{|c|c|c|c|c|c|c|c|c|}
\hline & & & \multicolumn{2}{|c|}{ 1: Final regression } & \multicolumn{2}{|c|}{ 2: Monopoly effect } & \multicolumn{2}{|c|}{ 3: Share of flights } \\
\hline & & & Coef. & T-stat & Coef. & T-stat & Coef. & T-stat \\
\hline \multirow{10}{*}{ Merger } & & $0-2$ years & $-20.81^{* * *}$ & 7.02 & $-26.63^{* * *}$ & -5.73 & $-10.96^{* * *}$ & -4.33 \\
\hline & & $2-5$ years & $-31.76^{* * *}$ & 8.80 & $-48.21^{* * *}$ & -8.90 & $-20.34^{* * *}$ & -6.98 \\
\hline & \multirow[t]{2}{*}{ Lagged HHI } & $0-2$ years & $20.44^{* * *}$ & 6.06 & $33.36^{* * *}$ & 4.16 & & \\
\hline & & 2-5 years & $34.87^{* * *}$ & 7.71 & $72.54^{* * *}$ & 7.56 & & \\
\hline & \multirow{2}{*}{ Lagged Share } & $0-2$ years & & & & & $8.06^{* *}$ & 2.85 \\
\hline & & 2-5 years & & & & & $20.93^{* * *}$ & 5.75 \\
\hline & \multirow{2}{*}{$\begin{array}{l}\text { Lagged monopoly } \\
\text { dummy }\end{array}$} & $0-2$ years & & & $-8.54^{*}$ & -2.19 & & \\
\hline & & $2-5$ years & & & $-26.40^{* * *}$ & -5.70 & & \\
\hline & \multirow{2}{*}{ Connections } & $0-2$ years & 0.03 & 0.63 & 0.03 & 0.54 & 0.03 & 0.65 \\
\hline & & 2-5 years & $0.20^{* * *}$ & 3.23 & $0.17^{* *}$ & 2.75 & $0.17^{* *}$ & 2.92 \\
\hline \multirow{5}{*}{\multicolumn{3}{|c|}{$\begin{array}{l}\text { Lagged HHI } \\
\text { Connections } \\
\text { Monopoly } \\
\text { Lagged Share } \\
\end{array}$}} & $22.99^{* * *}$ & 10.07 & $29.18^{* * *}$ & 6.97 & & \\
\hline & & & $1.74^{* * *}$ & 15.60 & $1.75^{* * *}$ & 15.64 & $1.57^{* * *}$ & 14.35 \\
\hline & & & & & $-3.73^{\dagger}$ & -1.95 & & \\
\hline & & & & & & & $55.61^{* * *}$ & 27.37 \\
\hline & & & \multicolumn{2}{|c|}{$\mathrm{R}^{2}=0.16$} & \multicolumn{2}{|c|}{$\mathrm{R}^{2}=0.18$} & \multicolumn{2}{|c|}{$\mathrm{R}^{2}=0.19$} \\
\hline
\end{tabular}

Note: significance levels: ${ }^{*}$ indicates significance at the $5 \%,{ }^{* *}$ at the $1 \%$ and ${ }^{* * *}$ at the $0.1 \%$ level. The standard errors are clustered on the OD pair and carrier combination. Fixed effects on airline-OD combinations, on year, on LCC*year and on month are included but are not shown. 
Table A.6: Differentiated effect of the 5 mergers added to the market and network structures model of Table 6

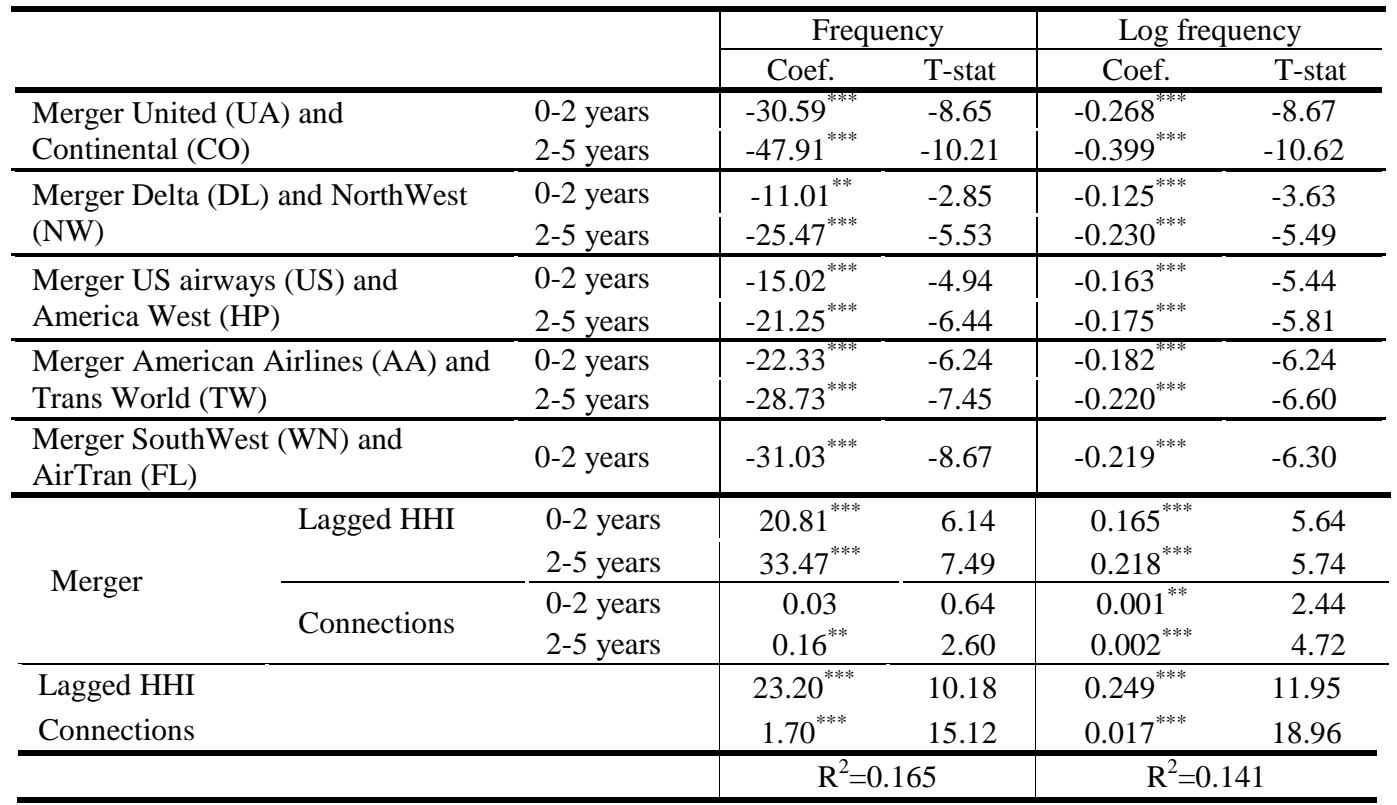

Note: significance levels: ${ }^{*}$ indicates significance at the $5 \%,{ }^{* *}$ at the $1 \%$ and ${ }^{* * *}$ at the $0.1 \%$ level. The standard errors are clustered on the OD pair and carrier combination. Fixed effects on airline-OD combinations, on year, on LCC*year and on month are included but are not shown.

Table A.7: Differentiated effect of the 5 mergers added to the pre-existing market structure model of Table 7

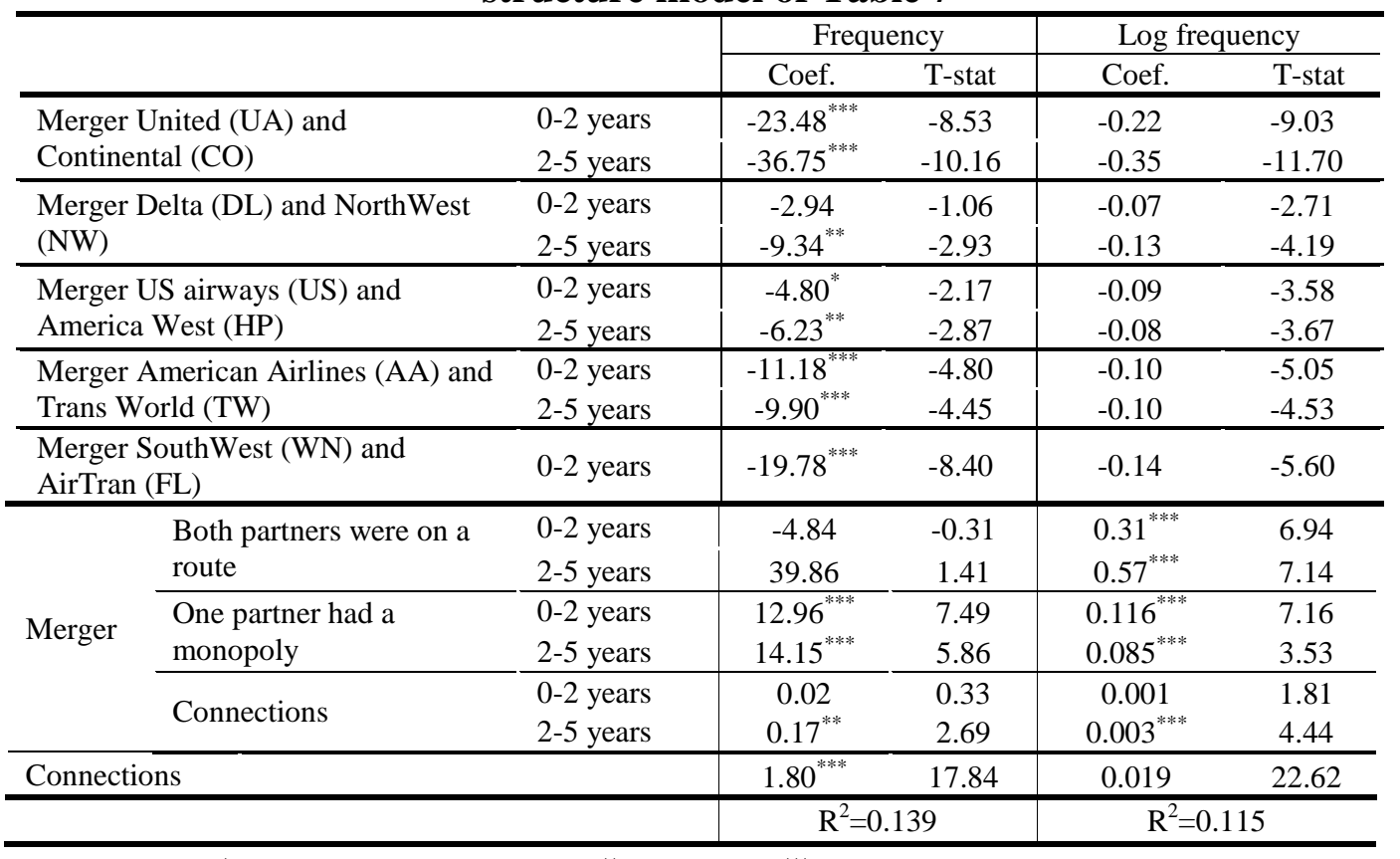

Note: significance levels: ${ }^{*}$ indicates significance at the $5 \%,{ }^{* *}$ at the $1 \%$ and ${ }^{* * *}$ at the $0.1 \%$ level. The standard errors are clustered on the OD pair and carrier combination. Fixed effects on airline-OD combinations, on year, on LCC*year and on month are included but are not shown.

\section{References}

Berry, S., Jia, P., 2010. Tracing the woes: An empirical analysis of the airline industry. American Economic Journal: Microeconomics, 2(3), 1-43.

Bilotkach, V., 2007. Airline partnerships and schedule coordination. Journal of Transport Economics and Policy, 41, 413425. 
Bilotkach, V., Fageda, X., Flores-Fillol, R., 2013. Airline consolidation and the distribution of traffic between primary and secondary hubs. Regional Science and Urban Economics, 43(6), 951-963.

Bilotkach, V., Hüschelrath, K., 2015. Balancing competition and cooperation: Evidence from transatlantic airline markets. ZEW Discussion Papers 15-059.

Borenstein, S., 1989. Hubs and high fares: dominance and market power in the US airline industry. The RAND Journal of Economics, 20(3), 344-365.

Borenstein, S., 1990. Airline mergers, airport dominance, and market power. The American Economic Review, 80(2), 400404.

Chen, Y., Gayle, P., 2013. Mergers and product quality: Evidence from the airline industry. MPRA Paper No. 51238. Accessed from https://mpra.ub.uni-muenchen.de/51238/ on 3 June 2016.

Czerny, A I., van den Berg, V.A.C., Verhoef, E.T., 2016. Carrier collaboration with endogenous fleets and load factors when networks are complementary. Transportation Research Part B: Methodological, 94, 285-297.

Economides, N., Salop, S.C., 1992. Competition and integration among complements, and network market structure. Journal of Industrial Economics, 40(1), 105-123.

Fan, Y., 2013. Ownership consolidation and product characteristics: A study of the US daily newspaper market. American Economic Review, 103, 1598-1628.

Focarelli, D., Panetta, F., 2003. Are Mergers Beneficial to Consumers? Evidence from the Market for Bank Deposits. American Economic Review, 93, 1152-1172.

Gayle, P.G., 2013. On the Efficiency of Codeshare Contracts Between Airlines: Is Double Marginalization Eliminated? American Economic Journal: Microeconomics, 5, 244-273.

Gayle, P.G., Le, H.B., 2013, .Measuring Merger Cost Effects: Evidence from a Dynamic Structural Econometric Model. Working paper of the Kansas State University, Department of Economics. Accesed from http://wwwpersonal.ksu.edu/ gaylep/Manuscript_September_2015_Gayle_Le_merger.pdf on 2 Februari 2017.

Gil, R., Kim, M., 2016. Does Competition Increase Quality? Evidence from the US Airline Industry. SRRN workingpaper (version of 17 January 2016). Accesed from SSRN: http://dx.doi.org/10.2139/ssrn.2617528 on 3 June 2016.

Halvorsen, R., Palmquist, R., 1980. The interpretation of dummy variables in semilogarithmic equations. American Economic Review, 70 (3), 474-475.

Ho, V., Hamilton, B.H., 2000. Hospital mergers and acquisitions: Does market consolidation harm patients? Journal of Health Economics, 19, 767-791.

Ito, H., Lee, D., 2007. Domestic codesharing, alliances and airfares in the U.S. airline industry. Journal of Law and Economics, 50, 355-380.

Kim, E.H., Singal, V., 1993. Mergers and market power: Evidence from the airline industry. American Economic Review, 83, 549-569.

Kwoka, J., Shumilkina, E., 2010. The price effect of eliminating potential competition: Evidence from an airline merger. Journal of Industrial Economics, 58(4), 767-793.

Luo, D., 2014. The price effects of the delta/northwest airline merger. Review of Industrial Organization, 44(1), $27-48$.

Morrison, S.A., 1996. Airline mergers: A longer view. Journal of Transport Economics and Policy, 30(3), 237-250.

Morrison, S.A., Winston, C., 1995. The Evolution of the Airline Industry. Washington, D.C., Brookings Institution Press.

Mutter, R.L., Romano, P.S., Wong, H.S., 2011. The effects of US hospital consolidations on hospital quality. International Journal of the Economics of Business, 18, 109-126.

Prince, J.T. Simon, D.H., 2015. The Impact of Mergers on Quality Provision: Evidence from the Airline Industry. Kelley School of Business Research Paper: No. 2014-03 (version of 9 October 2015). Accessed from http://dx.doi.org/10.2139/ssrn.2419611 on 6 June 2016.

Richard, O., 2003. Flight frequency and mergers in airline markets. International Journal of Industrial Organization, 21(6), 907-922.

Rijken, D., 2016. Impact of Airline Mergers on Quality. MSc Thesis, VU University, Amsterdam.

Romano, P.S., Balan, D.J., 2011. A retrospective analysis of the clinical quality effects of the acquisition of Highland Park Hospital by Evanston Northwestern Healthcare. International Journal of the Economics of Business, 18, 45-64.

Sapienza, P. 2002. The effects of banking mergers on loan contracts. Journal of Finance, 57, 329-367. 
